\title{
AWARENESS OF LATVIAN PREGNANT WOMEN ABOUT THE SAFETY OF MEDICINES DURING THE CHILD'S EXPECTATION
}

\author{
Valerija Maksane \\ Red Cross Medical College of Rīga Stradiņš University, Latvia \\ Elita Ardava \\ Red Cross Medical College of Rīga Stradiṇš University, Latvia \\ Oskars Onzevs \\ Turība University, Latvia
}

\begin{abstract}
Worldwide studies on the safety of medicines for pregnant women show that most women know which medicines to avoid during pregnancy. However, a large number of women are not aware that the use of medication during pregnancy can lead to adverse events. This type of studies has not been conducted in Latvia yet. The aim of this work is to find out the level of awareness among pregnant women in Latvia about the safety of the use of different medications during pregnancy, in order to clarify the ways of improving it. Quantitative and qualitative research methods have been used in this study. Between September 2018 and December 2019, 606 women were surveyed. Expert interviews led to conclusions on improving the education of pregnant women and pharmacy assistants. About $75 \%$ of women have been taking medicines during pregnancy. Usually it was 2-3 medicinal products. Approximately 10\% used 4 or more medicines. Most women surveyed are not aware that the use of medications during the second and third trimesters can have a negative effect on the mother or baby. Most women (78\%) wouldn't use medications without a doctor's advice, but $17 \%$ would if they consulted a pharmacist. Obtained results on the awareness of pregnant women showed that it is important to improve their knowledge of the safety of medicines. This can be achieved by improving the education program for pharmacy assistant pharmacists. A focus group discussion has been organised on this matter.
\end{abstract}

Keywords: awareness, pregnancy, safety of drugs.

\section{Introduction}

Often, the first place where pregnant women would ask questions about medicines and their use is a pharmacy. About $50 \%$ of pregnancies are unscheduled and often revealed when a woman has already taken some medications. Pregnant women often visit a pharmacy because it is the most accessible place to ask a pharmacist whether any harm to the foetus has been caused when taking medications. Data from the scientific literature show that pharmacists often refer 
pregnant women to their consulting physician without providing any information. This is due to the fact that pharmacists are often not prepared enough to provide information on teratology. However, if pharmacists provide information to pregnant women, in some cases, it is not sufficiently accurate and based on their own opinion and not on scientific evidence (Samuel \& Einarson, 2011).

A study on the safety of medicines in Saudi Arabia found that the majority of women (59.2\%) know which medicines should be avoided during pregnancy (Zaki \& Albarraq, 2014). However, a large part of women is not aware of that, so it is important that the pharmacist gives a proficient and accurate recommendation to them, helping to avoid the negative effects of medicines on the foetus. Recommending medicines harmful to pregnancy can lead to undesirable consequences, such as neonatal organ pathology or developmental disorders. It is possible to avoid this by assessing the need for use of medicines and correct usage of them, recommending the safest option.

A study that enrolled 19,000 women has shown that around 90\% of women took at least one medicine during pregnancy (Mitchell et al., 2011).

During pregnancy, a variety of food supplements containing vitamins and minerals are often used. Vitamins and minerals play a major role in foetal development, but overdose may have an opposite effect, for example, vitamin A in such cases leads to a teratogenic effect (Dibley \& Jeacocke, 2001). Therefore, when vitamins and minerals are administered to pregnant women, and when recommended by pharmacists, the doses should be followed and it is important that they are not exceeded.

The aim of this work is to find out the level of awareness among pregnant women in Latvia about the safety of the use of different medications during pregnancy, in order to clarify ways of improving it.

Quantitative and qualitative method has been used in this study. During the period from September 2018 to December 2019, a survey of 606 women was carried out. The study was conducted through social networks. To reach the required number of respondents, the questionnaire was placed in closed mothers' groups in social networks.

When results of the questionnaire were acquired, a discussion took place within the focus group. As a result, it was possible to put forward proposals to raise awareness among pregnant women about the use of medicines.

\section{Literature review}

There are no effective drugs known to have no side effects. This fact obliges the prescriber to always assess the benefits compared to the risks that the medicines might pose (Shcoen, Osborn, Doty, \& Bishop, 2007). This applies to all patients, but especially care should be taken with pregnant women, as all 
medicines should be avoided if possible during the first trimester and should only be prescribed if the expected maternal benefit is greater than the risk of foetal (Sachdeva, Patel, \& Patel, 2009). Although it is desirable to avoid medicines during pregnancy, it is often impossible and can be harmful because there are some pregnant women who suffer from chronic illnesses and new modern health problems that appear during pregnancy. Failure to comply with these conditions and diseases may have an impact on the mother and on the health of her child (Andrade, Gurwitz, Davis, \& Chan, 2004). A small number of drugs have been identified as teratogenic, but thousands of drugs have none. In only 3\% of cases, teratogenic effects are related to medicines (Koren, 2009). A doctor may prescribe some vitamins or minerals during pregnancy as food supplements, or medicines to treat common symptoms during pregnancy, such as headache, nausea, vomiting (Pange, 2006). Pregnant women may also be treated with other medicines that may cause an adverse effect on the foetus (Sorensan, Philips, \& Mutnick, 2004). In different countries, healthcare providers seek to ensure that pregnant women have adequate health awareness (Eiser \& Eiser, 1985; Marsack, Alsop, Kurinczuk, \& Bower, 1999). However, a number of studies have shown that women have a weak knowledge of the risks associated with medicines during pregnancy (Eiser et al., 1985; Marsack et al., 1999; Roth \& Taylor, 2001; Arnold et al., 2011).

According to the Food and Drug Administration classification, medicines are classified in 5 categories depending of their safety during pregnancy:

1) Category A. Safe drugs. Adequate, well-controlled human studies have been conducted and there has been no proven risk to the foetus during the 1st trimester, including the 2nd and 3rd trimesters;

2) Category B. Low-risk medicines. No adequate human studies have been performed, but animal studies have been conducted. Animal studies may show and may not present risks;

3) Category C. Unknown risk medicines. No qualitative studies have been performed in pregnant women, but studies in animals have shown adverse effects. In some situations, the benefits of taking this medicine may exceed their potential risks. Medicines may adversely affect the foetus, but do not cause birth defects;

4) Category D. Risky drugs. There are studies in pregnant women that have demonstrated a risk to the foetus. Drug use is associated with hereditary defects and irreversible consequences. In some cases, the benefits of this medicines are greater than the potential risks;

5) Category X. Medicines that are contraindicated to pregnant women. Studies in pregnant women have shown a risk to the foetus and/or studies in humans or animals have shown foetal abnormalities. Drug risks outweigh potential benefits (Leek \& Arif, 2019). 


\section{Methodology}

A questionnaire was used to conduct a survey among women living in Latvia who have been pregnant at least once. A total of 606 women were surveyed (9 women were under the age of 20; 101 women were aged 20-24; 227 women were aged 25-30; 269 women were older than 30). This survey was conducted between September 2018 and December 2019. The survey took place in the Web, on the Google platform. In order to reach the required number of respondents, it was placed in closed mothers' groups in social networks. The questionnaire consisted of 7 questions. There were questions about age, the number of medicines used during pregnancy, the sources of information from which women learned about the safety of medicines, and the question of which medicines may be dangerous during the different trimesters of pregnancy. In the course of the survey, women had to list some medicines that should be avoided during pregnancy, and the phrases (I agree; I do not agree; I neither agree nor disagree) that reflect their views the best regarding the various claims related to the safety of medicines.

Available sources of scientific literature, such as PubMed, Medscape, UpToDate, have been used in this study.

The discussion within the focus group led to conclusions on improving the level of education for pregnant women and pharmacy assistants in order to provide more insight into this issue than through a questionnaire or survey. The focus group consisted of 8 experts: a director of Pharmacy study programme in the Red Cross Medical College of Rīga Stradinš University, a lecturer of Pharmacy study programme at the Rīga Stradinšs University and 6 heads of pharmacies. The participants discussed ways to raise awareness among pregnant women reading the use of medicines and ways to improve lectures for future pharmaceutical professionals on the pharmaceutical care of pregnant women at the College. The focus group discussion lasted about 50-60minutes.

\section{Research results}

Questionnaire showed that the general awareness of the use of medicines in pregnant women is low. In this section, you can see more detailed results.

Figure 1 shows that the majority of respondents - 71\% - could name specific medicines that should be avoided during pregnancy. 36\% could name 1 medicine, while $35 \%-2$ or more. Most commonly, ibuprofen and antibiotics were mentioned. $29 \%$ of respondents couldn't name any medicines. A similar study conducted in Saudi Arabia found that about $60 \%$ of women could name medicines that should be avoided during pregnancy (Zaki et al., 2014). On the other hand, a similar study in Sudan showed that $50.6 \%$ of women could not name any medicines that should be avoided during pregnancy (Eldalo et al., 2015). 
Proceedings of the International Scientific Conference. Volume VI, May $22^{\text {th }}-23^{\text {th }}, 2020.324-333$

Compared to Saudi Arabia and Sudan, women in Latvia are more informed about medicines that should be avoided while pregnant.

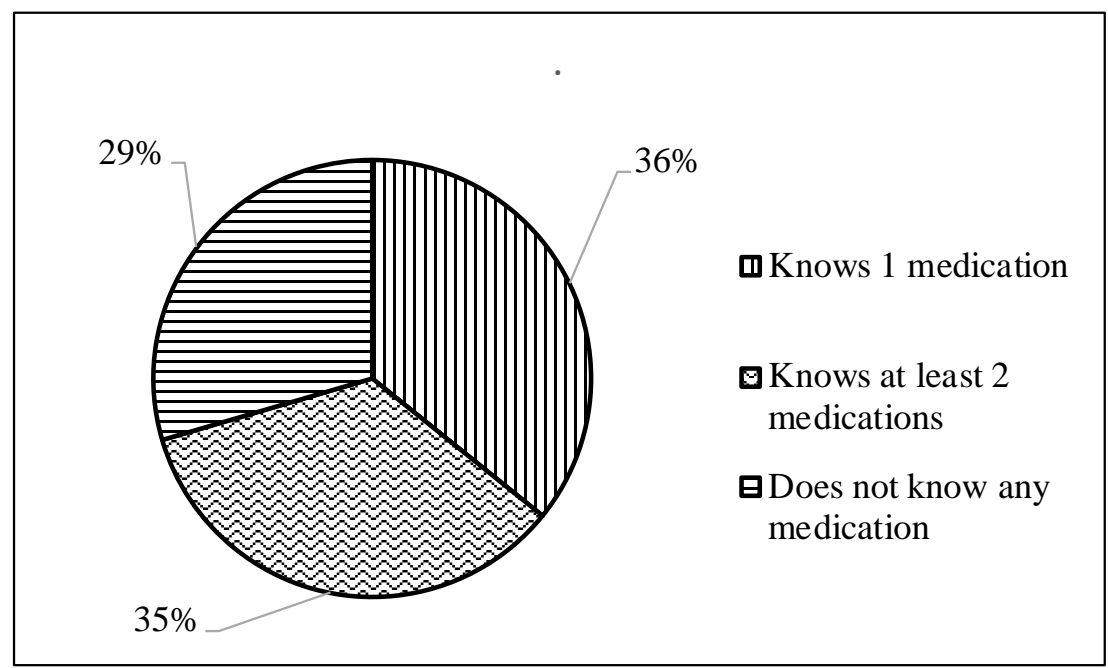

Figure 1 Responders' ability to name medicines that should be avoided during pregnancy

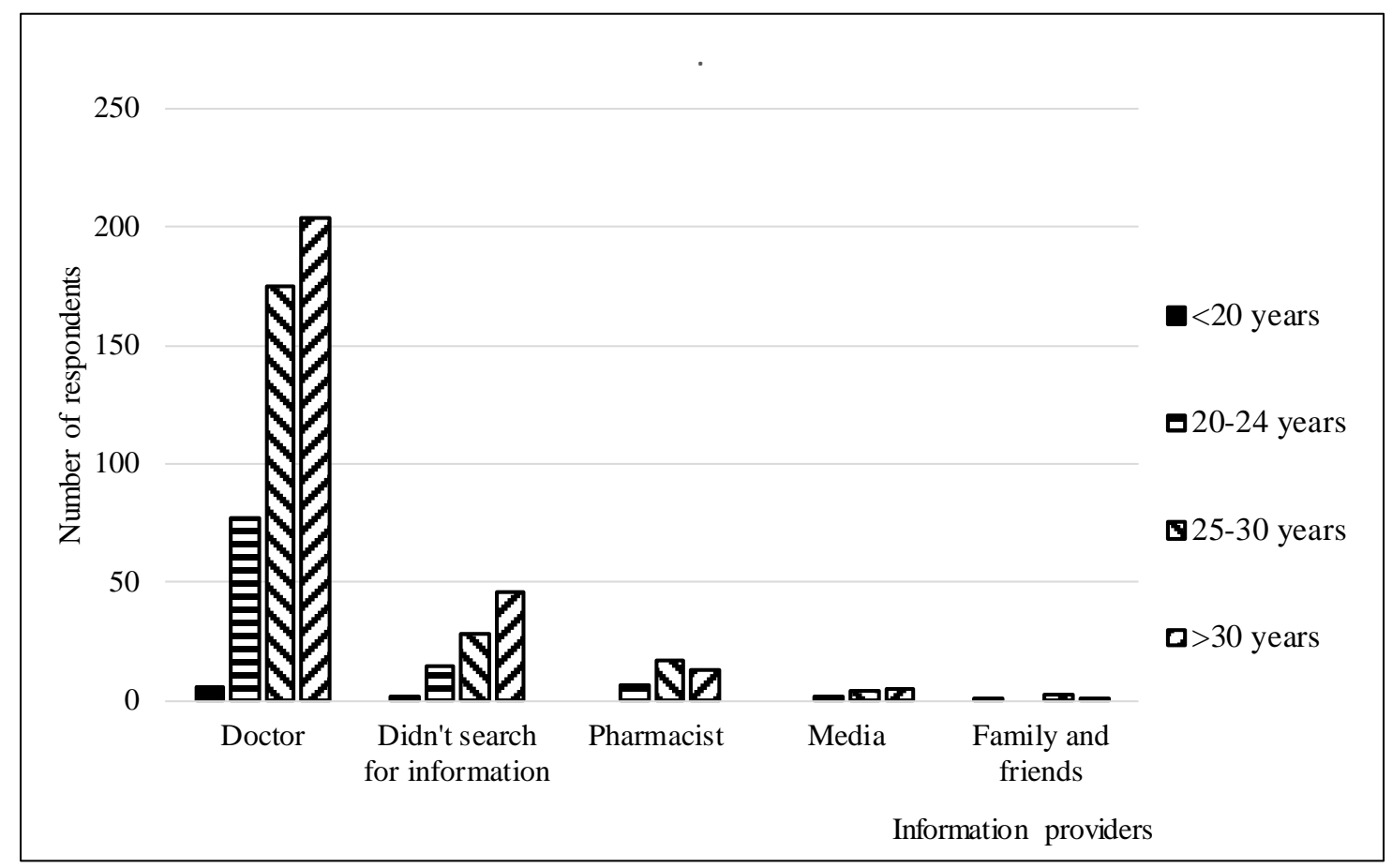

Figure 2 Sources of information on the safety of medicinal products during pregnancy, depending on responders' age

It is evident (see Fig. 2) that in most cases (76\% of cases) information about drug safety was obtained from a doctor. $6 \%$ of respondents asked the pharmacist for advice. $2 \%$ learned about the safety of medicines from the media, but a very small part - from friends and/or relatives. A similar study conducted in Sudan 
showed that $60.2 \%$ of respondents obtained information on the safety of medicines from a doctor, $34.4 \%$ from a pharmacist and $1.4 \%$ from the media (Eldalo et al., 2015). Another study in Saudi Arabia showed that $71.1 \%$ of surveyed obtained information on the safety of medicines from a doctor, $11 \%$ from a pharmacist, $5 \%$ from the media, 3\% from family members and/or friends (Zaki et al., 2014). Another study, which took place in Italy, showed that pregnant women obtained safety information in $81.3 \%$ of cases from a doctor, $46.9 \%$ from the media, and $14.7 \%$ from a pharmacist (Nevaro et al., 2018). In all these countries, the most common safety information during pregnancy is obtained from a doctor. However, pharmacists play a less important role in this matter in Latvia compared with Saudi Arabia, Sudan and Italy.

The question of which medicines are dangerous during the different trimesters of pregnancy had the option of selecting more than one response. Figure 3 shows that most of responders' think that medicines are dangerous during the first trimester of pregnancy (93\%). Nearly half, 39\%, said it could be dangerous to use medicines during the third trimester. And only 33\% of surveyed women responded that taking medications during the second trimester of pregnancy can be dangerous. The majority of responders were not aware that, during the second and third trimesters of pregnancy, medications may have a negative effect on the mother or/and the child. It appears that women who did not take medications during pregnancy are more informed that the drugs can be dangerous in all trimesters of pregnancy. In a similar study conducted in Sudan, the results were as follows: $66.8 \%$ (334) thought medications are dangerous during the first trimester; $27 \%$ did not know the answer to that question, while others believed that taking medications is dangerous during the second or third trimester of pregnancy (Eldalo et al., 2015). Compared to Sudan, women in Latvia are better informed about the dangers of medicines during pregnancy.

The majority of women, 75\%, have used medicines during pregnancy (taking 2 to 3 medicines was the most common case). Compared to a similar study conducted in Sudan, women in Latvia take medicines less. In Sudan, 84.8\% of women had taken medications during pregnancy (Eldalo et al., 2015). Meanwhile, a similar study in Saudi Arabia has found that only $40.1 \%$ of women used medicines during pregnancy (Zaki et al., 2014). Another study carried out in Italy showed that $59.6 \%$ of women were taking medicines during pregnancy (Nevaro et al., 2018). Compared to Saudi Arabia and Italy, in Latvia and Sudan, medicines are used more often among pregnant women.

If woman had responded that she had been taking medications during pregnancy, she had been asked to list the medicines she had taken. The most commonly used group of medical treatment products was vitamins (magnesium, iron and complex vitamins were most mentioned). The second group of the most commonly used drugs was painkillers and antispasmodic. The data obtained in 
Latvia differ from the data obtained in a similar study in Saudi Arabia. Paracetamol was mentioned there in $13.2 \%$ of cases (11.06\% in this study) and vitamins in $13.2 \%$ of cases (53.05\% in this study). Antibiotics were mentioned in $2.6 \%$ of cases (5.19\% in this study), antihistamines in $1.3 \%$ (in this study $1.13 \%$ ) (Zaki et al., 2014). Vitamin-containing products in Latvia have been used approximately 4 times more frequently than in pregnant women in Saudi Arabia. Antibiotics have also been used about 2 times more frequently. Paracetamol and antihistamines have been used in approximately the same amount.

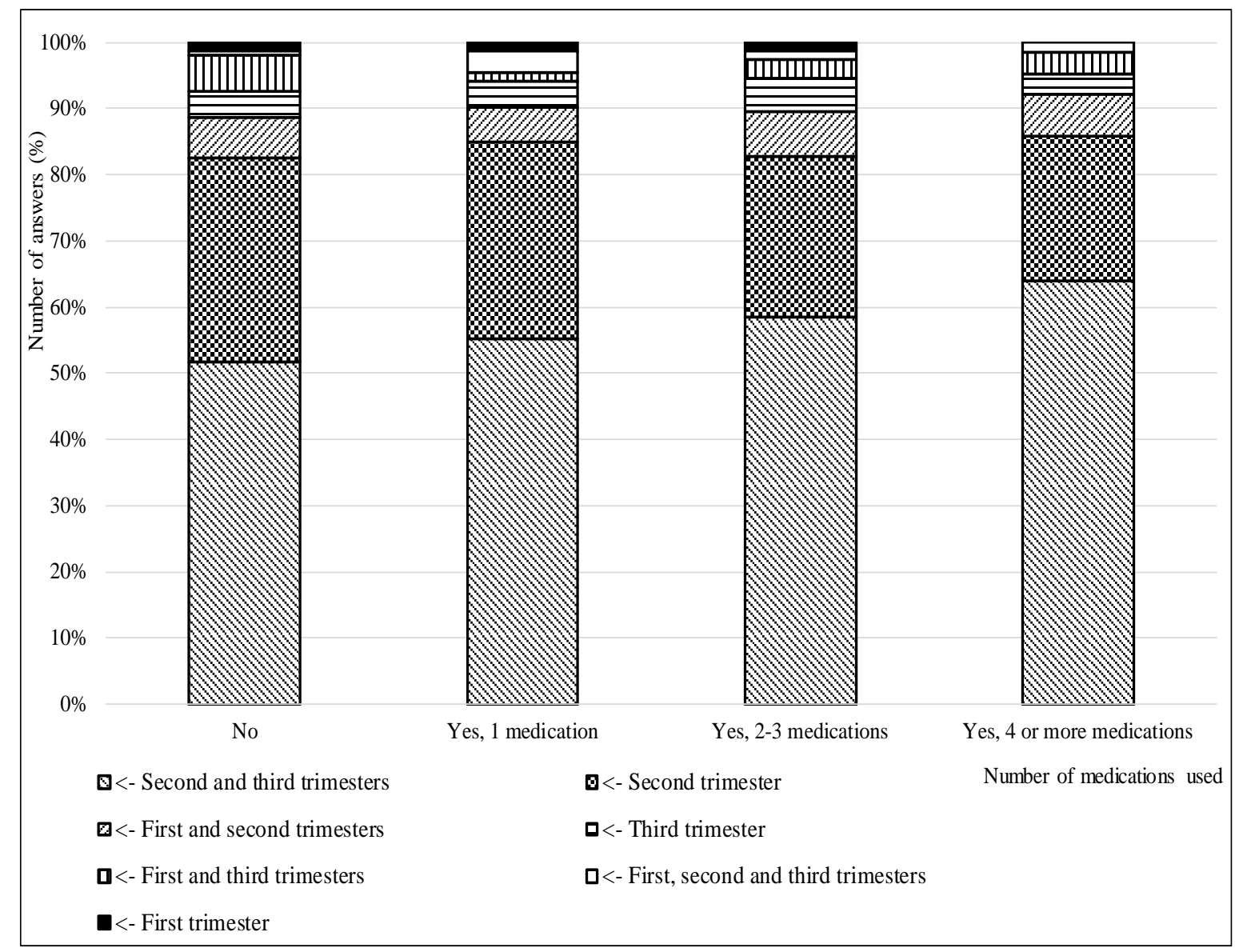

Figure 3 Respondents' awareness of the hazardous effects of medicines during different periods of pregnancy, depending on whether medicines have been administered during pregnancy

Women had to note if they agree with the given statement. Figure 4 shows that the majority of women, $53 \%$, do not agree that all medicines can be dangerous to the foetus. However, $27 \%$ of women agree with this statement and only $20 \%$ were not convinced and chose to "neither agree nor disagree". A similar study conducted in Sudan yielded the following results: 12.2\% agreed; $80.6 \%$ disagreed; 7.2\% neither agreed nor disagreed (Eldalo et al., 2015). Meanwhile, 
the results of the study in Saudi Arabia were the following: 59.2\% agreed; $22.4 \%$ disagreed; 18.4\% neither agreed nor disagreed (Zaki et al., 2014). Another study took place in India. In this study, women had to specify their thoughts about the same statement, only the answers were more detailed. The answers were as follows: $2.6 \%$ responded that medicines can be dangerous for the mother; $68.46 \%$ responded that medicines can be dangerous for the foetus; $24.55 \%$ replied that medicines can be dangerous for both the mother and the child; $4.39 \%$ replied that medicines are safe during pregnancy (Kureshee \& Dhande et al., 2013). There were significant differences in data collected in different countries. Data from Latvia shows that the majority of women believe that not all medicines are dangerous to the foetus, but in Sudan women are even more confident about it. In Saudi Arabia, most women think all medicines can be dangerous to the foetus. In India, too, most respondents think that medicines are dangerous to the foetus, and only a small percentage of women consider them safe.

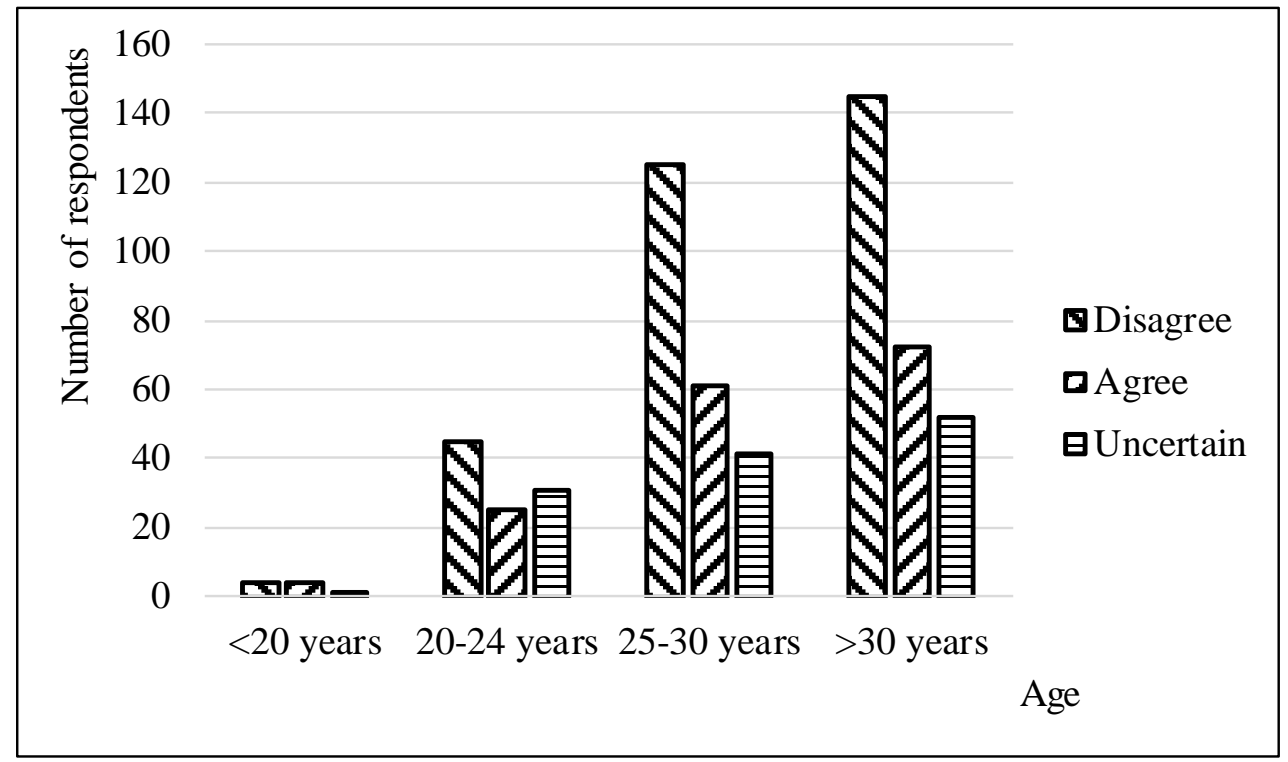

Figure 4 Respondents' views on the claim "All medicines can be dangerous to the foetus" depending on age

\section{Analysis of obtained results in the focus group}

Experts agreed that in order to raise awareness among pregnant women about the safety of medicines during pregnancy, the responsible institutions of country should organize a set of measures. These measures could include special groups in social networks intended for Latvian women. These groups would have the opportunity to learn about the effects of various medicines on the foetus from health care professionals. This information would be secure, reliable, and based on more recent medical research. It would also be valuable to create informational materials - booklets, promotional materials, 1 day courses for emerging mothers 
on the subject. The gynaecologist should be required to inform the patient on the first visit that there are medicines that are not safe during the pregnancy and to enrol the patients into the state-reimbursed courses on the subject.

In the course of the conversation, the focus group came to conclusion that the changes to the lectures regarding pregnant women for the future pharmaceutical professionals at Red Cross Medical College of Rīga Stradiňš University would be valuable. The lecture is currently devoted not only to the acquire information about pregnant women, but also about seniors and the paediatric population. There is a group work for students during the lecture: they have to prepare a paper on one of three topics: pregnant women, seniors, or children. The focus group decided that dedicating a full lecture to the subject of pregnancy would be more feasible. In the first part of the lecture, the lecturer would tell students about the most commonly used medicines in difference conditions (such as cold, diarrhoea, wounds, etc.). He would tell about which medicines can be used and which should be avoided. The lecturer would tell which category each medicine belongs to by FDA classification system (A, B, C, $\mathrm{D}, \mathrm{X}$ ). In the second part of the lecture, students would have the opportunity to acquire practical skills in the pharmaceutical care of pregnant women, modelling different situations and creating dialogues. Students would be given homework to write a paper on medicines during pregnancy, which would require them to find information on the subject themselves. Particular attention should be paid to the reliability of the sources and to how new and up-to-date the used articles are.

\section{Conclusions}

According to the results of survey, women in Latvia are poorly informed about the hazards of medicine usage during pregnancy. This fact is important if we know that the majority of women take medicines during pregnancy. Unfortunately, most think that only medicines used during the 1st trimester can have a negative effect on the new-born. In the light of this and other data generated by the questionnaire, it was decided within the focus group that it was crucial to organize educational events for emerging mothers on this topic, such as groups in social networks for Latvian women, informative leaflets and promotional materials, 1 day educational courses. The focus group also came to the conclusion that the lecture about the treatment of pregnant women for the future pharmaceutical professionals at the Red Cross Medical College of Rīga Stradiñš University is needed to be improved, with a greater emphasis on the skills and the collection of up-to-date information on the use of medicines during pregnancy. This would be important because pharmaceutical professionals are also health professionals, and their role is to transfer information to the citizens on healthrelated topics. 
Maksane et al., 2020. Awareness of Latvian Pregnant Women about the Safety of Medicines

During the Child's Expectation

\section{References}

Andrade, S.E., Gurwitz, J.H., Davis, R.L., Chan, K.A. et al. (2004). Prescription drug use in pregnancy. American Journal of Obstetrics \& Gynecology, 191(2), 398-407. DOI: 10.1016/j.ajog.2004.04.025

Arnold, C.L., Davis, T.C., Berkel, H.J., Jackson, R.H. et al. (2011). Smoking status, reading level, and knowledge of tobacco effects among low-income pregnant women. Preventive medicine, 32(4), 313-320. DOI: 10.1006/pmed.2000.0815

Dibley, M.J., \& Jeacocke, D.A. (2001). Safety and Toxicity of Vitamin A Supplements in Pregnancy. Food and Nutrition Bulletin, 22(3), 248-266. DOI: 10.1177/15648265 0102200304

Eiser, C., \& Eiser, J.R. (1985). Health education need of primigravidae. Child: Care, Health and Development, 11, 53-60. DOI: 10.1111/j.1365-2214.1985.tb00450.x

Eldalo, A., Yousif, M., \& Siraj, N. (2015). Pregnant Women's Awareness and Perception About Medicines. Latin American Journal of Pharmacy, 34(5), 869-874.

Koren, G. (2009). Special aspects of perinatal and pediatric pharmacology. In Basic and clinical pharmacology, 11th. ed. (1025-1036). New Delhi: Tata McGraw Hill.

Kureshee, N.I., \& Dhande, P.P. (2013). Awareness of Mothers and Doctors about Drugs Utilization Pattern for Illnesses Encountered during Pregnancy. Journal of Clinical and Diagnostic Research for doctors, 7(11), 2470-2474. DOI: 10.7860/JCDR/ 2013/6329.3582

Leek, J.C., \& Arif, H. (2019). Pregnancy Medications. Treasure Island: StatPearls Publishing.

Marsack, C.R., Alsop, C.L., Kurinczurk, J.J., \& Bower, C. (1999). Pre-pregnancy counselling for the primary prevention of birth defects: rubella vaccination and folate intake. The Medical Journal of Australia, 170, 143-144.

Mitchell, A.A., Gilboa, S.M., Werler, M.M. et al. (2011). Medication Use During Pregnancy, With Particular Focus On Prescription Drugs: 1976-2008. American Journal of Obstetrics and Gynecology, 205(1), 51.e1-51.e8. DOI: 10.1016/j.ajog.2011.02.029

Nevaro, M., Vezzosi, L., Santagati, G., \& Angelillo, I.F. (2018). Knowledge, attitudes, and practice regarding medication use in pregnant women in Southern Italy. Journals Plos One, 13(6), 0198618. DOI: 10.1371/journal.pone.0198618

Pange, B.L. (2006). Drugs in Pregnancy and Lactation. Text book of Therapeutics, Drug and Disease Management, 8th ed. Philadelphia: Lippincott William Wilkins.

Roth, L.K., \& Taylor, H.S. (2001). Risks of smoking to reproductive health: assessment of women's knowledge. American Journal of Obstetrics \& Gynecology, 184(5), 934-939. DOI: $10.1067 / \mathrm{mob} .2001 .112103$

Sachdeva, P., Patel, B.G., \& Patel, B.K. (2009). Drug use in pregnancy; a point to ponder. Indian Journal of Pharmaceutical Sciences, 71(1), 1-7. DOI:10.4103/0250-474X.51941

Samuel, N., \& Einarson, A. (2011). Medication management during pregnancy: role of the pharmacist. International Journal of Clinical Pharmacy, 33(6), 882-885. DOI: 10.1007/s11096-011-9560-8

Sorensan, M.K., Philips, B.B., \& Mutnick, A.H. (2004). Drug use in specific patient populations: Pediatric, Pregnant, Geriatric. Comprehensive Pharmacy Review, 5th ed. Philadelphia: Lippincott William Wilkins.

Zaki, N.M., \& Albarraq, A.A. (2014). Use, attitudes and knowledge of medications among pregnant women: A Saudi study. Saudi Pharmaceutical Journal, 22(5), 419-428. DOI: 10.1016/j.jsps.2013.09.001 